\title{
Quebec medical students strike at their own pace
}

About 2700 Quebec medical students joined a province-wide strike by 185000 students protesting the province's decision to cut $\$ 103$ million in bursaries and loans.

The action ended Apr. 2 when the province agreed to dedicate $\$ 482$ million over 5 years to a bursary program, beginning in September 2006.

Cutting classes could have jeopardized the year for students at Quebec's 4 medical schools, - but this was a risk some were will守 ing to take. "We were on strike for 6 days," says Xavier Huppé, gresident of the Regroupement des étudiants en médicine de l'Université de Laval. "The head $\ddot{\vec{\sigma}}$ of the faculty said we would be all $\curvearrowright$ right and that we could learn on our own for the time being," However, there was soon a "significant divide" between students, forcing an end to the protest "as the majority no longer favoured being on strike."

At the Universite de Sherbrooke, 266 medical students voted in favour of a strike, yet only about 70 actually participated in the 48-hour action. "I don't know what happened," medical student association president Fahamia Koudra said.

During the recent protests, Quebec Education Minister, Jean-Marc Fournier initially proposed an alternative financial assistance program to help the $35 \%$ poorest students at the end of their studies. - Christine Chéné, Ottawa

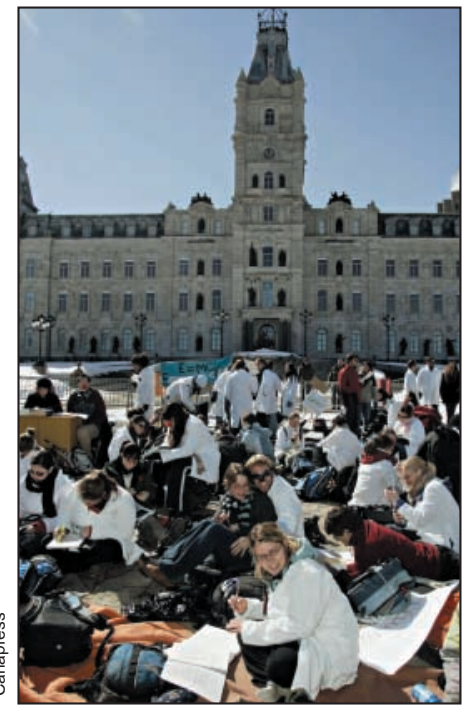

Medical students sit in at the Quebec legislature to protest government grant cuts.

\section{Poehlman Case}

\section{Université de Montréal in the dark about fraud}

The executive director of the Canada Research Chairs program says it's understandable that neither that organization nor the Université de Montréal were informed about a fraud investigation concerning a professor they hired to head a nutrition and metabolism lab.

Eric T. Poehlman was already under investigation in the United States for falsifying data when the Université de Montréal hired him in 2001 and the Canada Research Chairs awarded him a \$1-million chair in nutrition and metabolism.

Poehlman was subsequently awarded another \$200 000 in grants from the Canada Foundation for Innovation and the Canadian Institutes of Health Research to establish a metabolic research unit and biomedical mass spectrometry facility.

"You're innocent until proven guilty, I guess," says Dr. John ApSimon, executive director of the Canada Research Chairs program.

Poehlman pleaded guilty Apr. 5 to fraudulently obtaining a
US\$542 000 grant from the National Institutes of Health (NIH) by fabricating data on menopause, aging and hormone replacement. $\mathrm{He}$ was under investigation for fabricating data in 17 US applications that yielded him roughly US\$2.9 million in grants while employed by the University of Vermont College of Medicine (1987-1993 and 1996-2001) and the University of Maryland in Baltimore (1993-1996).

Citing "legal considerations," the Université de Montréal would not say whether they checked Poehlman's references or talked to officials at the University of Vermont prior to hiring him. Université de Montréal lawyers are considering pursuing a case of malfeasance that might result in recovering some monies from Poehlman.

"What I can tell you is he was hired by the university August 1st, 2001, and we were informed of the situation following the public retraction of one of his scientific articles in October 2003," says university spokesman Mark Tulin.
In a 1995 article (Ann Intern Med 1995;123 [9]:673-5), Poehlman linked menopause with slowed metabolism in 35 women. The article was retracted after the journal learned that Poehlman fabricated test results for 32 of the women.

The retraction prompted the Université de Montréal to contact officials at the University of Vermont who said that "privacy law" prevented them from disclosing information about Poehlman, says Tulin.

By May 2004, the university had stripped Poehlman of his research chair and professorship. He officially resigned on Jan. 22 when his contract expired.

Poehlman, who will be sentenced in the US on July 18, has already agreed to pay US\$180 000 to settle a civil complaint related to the grant applications he filed while in Vermont. He could face up to 5 years in prison on the criminal fraud charge, and a US\$250 000 fine. Other sanctions include a lifetime ban on receiving public health research monies. - Wayne Kondro, Ottawa 